\title{
Bcll glucocorticoid receptor polymorphism in relation to cardiovascular variables: the Hoorn and CODAM studies
}

\author{
Dirk van Moorsel 1,7,9, Marleen M J van Greevenbroek ${ }^{2,10}$, Nicolaas C Schaper 1,10,11, \\ Ronald M A Henry ${ }^{2,10}$, Charlotte C Geelen ${ }^{3}$, Elisabeth F C van Rossum ${ }^{4}$, Giel Nijpels ${ }^{5}$, \\ Leen M 't Hart ${ }^{6,8}$, Casper G Schalkwijk ${ }^{2,10}$, Carla J H van der Kallen ${ }^{2,10}$, Hans \\ P Sauerwein ${ }^{1,9}$, Jacqueline M Dekker ${ }^{5}$, Coen D A Stehouwer ${ }^{2,10}$ and Bas Havekes 1,7,9 \\ ${ }^{1}$ Department of Internal Medicine, Division of Endocrinology, Maastricht University Medical Center, PO Box 5800, \\ 6202 AZ Maastricht, The Netherlands, ${ }^{2}$ Department of Internal Medicine, Maastricht University Medical Center, \\ 6202 AZ Maastricht, The Netherlands, ${ }^{3}$ Adelante Center of Expertise in Rehabilitation and Audiology, 6432 CC \\ Adelante, Hoensbroek, The Netherlands, ${ }^{4}$ Department of Internal Medicine, Division of Endocrinology, Erasmus \\ MC, University Medical Center Rotterdam, 3000 CA Rotterdam, The Netherlands, ${ }^{5}$ Department of Epidemiology \\ and Biostatistics and the EMGO Institute for Health and Care Research, VU University Medical Center, 1007 MB \\ Amsterdam, The Netherlands, ${ }^{6}$ Department of Molecular Cell Biology, Leiden University Medical Center, 2300 RC \\ Leiden, The Netherlands, ${ }^{7}$ Department of Human Biology, Maastricht University Medical Center, 6200 MD \\ Maastricht, The Netherlands, ${ }^{8}$ Section Molecular Epidemiology, Leiden University Medical Center, 2300 RC Leiden, \\ The Netherlands, ${ }^{9} \mathrm{School}$ of Nutrition and Translational Research in Metabolism (NUTRIM), Maastricht, \\ The Netherlands, ${ }^{10} \mathrm{School}$ for Cardiovascular Diseases Maastricht (CARIM), Maastricht, The Netherlands and \\ ${ }^{11}$ School for Public Health and Primary Care (CAPHRI), Maastricht, The Netherlands
}

Correspondence should be addressed to B Havekes Email bas.havekes@mumc.nl

\begin{abstract}
Objective: Excess glucocorticoids are known to cause hypertension and cardiovascular disease (CVD). The Bcll glucocorticoid receptor (GR) polymorphism increases glucocorticoid sensitivity and is associated with adverse metabolic effects. Previous studies investigating cardiovascular implications have shown inconsistent results. Therefore, the aim of the present study was to investigate the association of the $B c / l$ polymorphism with blood pressure, atherosclerosis, low-grade inflammation, endothelial dysfunction, and prevalent CVD.
\end{abstract}

Design: Observational cohort study, combining two cohort studies designed to investigate genetic and metabolic determinants of CVD.

Methods: We genotyped 1228 individuals (aged 64.7 years \pm 8.5 ) from the Cohort on Diabetes and Atherosclerosis Maastricht (CODAM) study and Hoorn study for the $B c / l$ polymorphism. We measured blood pressure, ankle-brachial index (ABI), and carotid intima-media thickness (cIMT). Low-grade inflammation and endothelial dysfunction scores were computed by averaging $Z$-scores of six low-grade inflammation markers and four endothelial dysfunction markers respectively. Prevalent CVD was assessed with questionnaires, hospital records, ECG, and ABI.

Results: Homozygous carriers (GG) had higher mean arterial pressure (103.8 $\pm 12.4 \mathrm{mmHg}$ vs $101.6 \pm 12.2 \mathrm{mmHg}$ (mean \pm s.D.); $P<0.05$ ) compared with non-carriers (CC). Homozygous carriers had lower ABI compared with heterozygous carriers (CG) $(1.08 \pm 0.13$ vs $1.11 \pm 0.14 ; P<0.05)$. After adjustment for all covariates in the full model, the association with $A B I$ was no longer significant. $B c / l$ was not associated with systolic blood pressure, CIMT, low-grade inflammation, endothelial dysfunction, and prevalent CVD.

Conclusions: The $B C / l$ polymorphism of the GR gene may contribute to an unfavorable cardiovascular profile; however, the effects on cardiovascular variables appear to be limited and partly mediated by the metabolic phenotype exerted by $B c / l$.

(c) 2015 European Society of Endocrinology Printed in Great Britain
European Journal of

Endocrinology

(2015) $173,455-464$
Published by Bioscientifica Ltd 


\section{Introduction}

Glucocorticoids (e.g. cortisol) are secreted by the adrenal cortex and exert their effects by binding to the glucocorticoid receptor (GR). Effects of glucocorticoids are numerous and complex. Apart from metabolic actions (e.g. increased gluconeogenesis, insulin resistance, and lipolysis), glucocorticoids have a role in the complex interplay between pro- and anti-inflammatory pathways (1) and exert multiple vascular effects. Glucocorticoids increase blood pressure by enhancing sensitivity of vascular smooth muscle to catecholamines and angiotensin II, by increasing angiotensinogen synthesis, by reducing nitric oxidemediated endothelial dilatation and by sodium retention in the distal nephron $(2,3)$. Consequently, chronic exposure to high doses of endogenous or exogenous glucocorticoids often results in an unfavorable metabolic profile and cardiovascular disease (CVD) $(4,5,6,7)$.

Interestingly, efficacy and side effects of administered glucocorticoids are highly variable among individuals, whereas glucocorticoid sensitivity at an individual level appears rather stable (8). Part of the inter-individual variability of glucocorticoid effects is believed to be caused by polymorphisms in the GR gene (9). One of the most common functional polymorphisms (allele frequency $35 \%)$ in the GR gene is the BclI polymorphism (rs41423247) (9), consisting of a $\mathrm{C} \rightarrow \mathrm{G}$ substitution, 646 nucleotides downstream from exon 2 . The BclI polymorphism is associated with an increased sensitivity to glucocorticoids (10) and recently we showed that homozygous carriers of this polymorphism have more abdominal obesity (11), which may contribute to adverse cardiometabolic effects.

Although cardiovascular effects of the BclI polymorphism have been investigated before, inconsistent results were obtained and most studies were performed in selected patient populations. Some studies found systolic blood pressure (SBP) to be increased for BclI carriers $(12,13)$ and homozygous carriers of the BclI polymorphism (GG) were more common in a group of young adults with higher personal and parental blood pressure (14). Some larger studies, however, did not find this association $(10,15,16)$. One study evaluated the effect of multiple GR gene polymorphisms on blood pressure across different ethnic groups, but found no associations with $B c l I$ (17). With regard to CVD, no association between $B c l$ I and myocardial infarction, coronary heart disease or carotid intima-media thickness (cIMT) was found in two cohort studies in older individuals $(18,19)$. In contrast, in a large cohort study of individuals with familial hypercholesterolemia, $B c l$ I was associated with CVD in men (16) and $B c l$ l was associated with higher cIMT in individuals referred for coronary angiography (20).

Chronic low-grade inflammation and endothelial dysfunction play an important role in the pathobiology of $\operatorname{CVD}(21,22)$. Interestingly, so far only one study specifically addressed the role of the $B c l$ polymorphism in chronic low-grade inflammation but did not find a significant association (18). Whether carriers of this polymorphism display greater endothelial dysfunction has not been studied to date.

In view of the above, we conducted the present study in a large sample of two metabolically well-defined Dutch cohort studies designed to investigate the association between metabolic variables and CVD. The objective of our study was to investigate whether the presence of the $B c l$ polymorphism is associated with blood pressure, cIMT, ankle-brachial index (ABI), and prevalent CVD. In addition, we studied its relation with chronic low-grade inflammation and endothelial dysfunction. We hypothesized that the minor G-allele of the $B c l$ l polymorphism is associated with an unfavorable vascular profile.

\section{Methods}

\section{Study populations}

The study population consisted of individuals from the 2000 Hoorn study follow-up examination (23) and the baseline examination of the Cohort on Diabetes and Atherosclerosis Maastricht (CODAM) study (24). Both studies had a similar data collection research protocol and they have been used as a combined cohort before $(11,25)$.

Briefly, the Hoorn study started in 1989 and is a population-based cohort study of glucose metabolism, CVD risk factors and complications $(n=2484)$. A follow-up examination was performed among 822 individuals in 2000-2001, consisting of 648 surviving individuals of the baseline cohort and a group of 174 individuals with type 2 diabetes mellitus (T2DM) from the Hoorn Screening study (23). The CODAM study is an ongoing cohort study that started in 1999-2000, designed to investigate the effects of glucose metabolism, obesity, blood lipids, lifestyle, and genetic factors on CVD and mortality (24). It consists of 574 individuals selected on the basis of an elevated risk for T2DM and CVD from a large population-based cohort who had undergone a glucose metabolism screening test, as described elsewhere (24). 
The present study consisted of 1228 individuals (543 from CODAM and 685 from the Hoorn study) who were available for genotyping of the BclI polymorphism. The study was approved by the Medical Ethics Committees of the VU University Medical Center (Hoorn study) or the Maastricht University Medical Center (CODAM study), and all individuals gave written informed consent.

\section{Blood pressure measurements}

Brachial SBP and diastolic blood pressure (DBP) were assessed with an oscillometric device (Press-Mate, BP8800; Colin Medical Instruments Corp., San Antonio, TX, USA, in the Hoorn study and Speidel \& Kelly Maxi Stabil 3, Jungingen, Germany, in the CODAM study) $(24,26)$. Mean arterial pressure (MAP) was calculated as $((2 / 3 \times$ $\mathrm{DBP})+(1 / 3 \times \mathrm{SBP}))$.

\section{Markers of atherosclerosis and CVD prevalence}

Carotid IMT was measured in the carotid artery with ultrasound imaging (Ultramark 4+, Advanced Technology Laboratories, Bothel, WA, USA in the CODAM study and Pie 350 Series; Pie Medical BV, Maastricht, The Netherlands in the Hoorn study). For the ABI, SBP was measured in the brachial, dorsalis pedis, and posterior tibial arteries on both sides with a Doppler device. The ABI was calculated for each leg by dividing the highest ankle SBP by the highest brachial SBP. We used the lowest ABI of either leg for the analysis. Individuals with an ABI of more than $1.5(n=4)$ were excluded from the ABI analyses, since elevated ABI values may represent vascular stiffness (27).

Prevalent CVD was defined as a history of myocardial infarction, stroke or transient ischemic attack, nontraumatic limb amputation, coronary or peripheral artery bypass, angioplasty or signs of infarction or ischemia on a 12-lead ECG (Minnesota codes 1-1, 1-2, 1-3, 4-1, 4-2, 4-3, $5-1,5-2,5-3$, or $7-1)$ or an ABI of $<0.9$ in either leg $(24,28)$.

\section{Markers of low-grade inflammation and endothelial dysfunction}

Plasma markers of low-grade inflammation (C-reactive protein (CRP), interleukin 6 (IL6), interleukin 8 (IL8), tumor necrosis factor alpha (TNF $\alpha)$, serum amyloid A (SAA), and soluble intercellular adhesion molecule 1 (sICAM1)) and plasma markers of endothelial dysfunction (soluble E-selectin (sE-selectin) and soluble vascular cell adhesion molecule 1 (sVCAM1)) were measured by multiarray based on electro-chemiluminescence technology
(MesoScaleDiscovery, SECTOR Imager 2400, Gaithersburg, MD, USA) as previously described for Hoorn (29) and CODAM (30). In CODAM, IL6, SAA, sICAM1, sE-selectin, and sVCAM1 were also measured by ELISA and CRP was also measured in serum by high-sensitivity immunoturbidimetry (31). Values obtained by ELISA or immunoturbidimetry assay were calibrated on the values obtained by multi-array and the calibrated and multi-array values were averaged for CODAM (30). von Willebrand factor (vWF) was determined in citrated plasma by means of ELISA (29).

\section{Single-nucleotide polymorphism analysis}

The $B c l$ I restriction fragment length polymorphism (rs41423247) is a C/G (2.3 and $4.5 \mathrm{~kb}$ ) single-nucleotide polymorphism located in intron 2 of the GR gene (NR3C1), 646 nucleotides downstream from exon 2 (10). Determination of the $B c l$ l polymorphism was performed by allelic discrimination with the use of TaqMan Genotyping Master Mix (Applied Biosystems) using probes as previously described $(10,11)$.

\section{Statistical analysis and study power}

Data were analyzed with the use of IBM Statistical Package for Social Sciences for MAC, version 21 (SPSS, Inc.). HardyWeinberg equilibrium was determined using a $\chi^{2}$ test. Variables with a skewed distribution (CRP, IL6, IL8, TNF $\alpha$, SAA, sICAM1, vWF, sE-selectin, and sVCAM1) were natural log-transformed prior to further analyses.

To obtain a robust measure of overall inflammation and endothelial dysfunction we computed composite scores as described before $(30,32,33)$. With these composite scores we reduce biological variability and random error of each individual variable, and we gain statistical efficiency. The scores are calculated by first computing the $Z$-score for each individual variable ((individual value-population mean)/population s.D.) and next averaging the $Z$-scores for both the inflammation and endothelial dysfunction variables. The inflammation score consists of the variables CRP, IL6, IL8, TNF $\alpha$, SAA, and sICAM1, and the endothelial dysfunction score consists of the variables sICAM1, vWF, sE-selectin, and sVCAM1. sICAM1 is considered a marker both for lowgrade inflammation and for endothelial dysfunction, as it is expressed by both monocytes and endothelial cells (34).

Logistic and linear regression analyses were used as appropriate to compare levels of blood pressure, cIMT, $\mathrm{ABI}$, scores for inflammation and endothelial dysfunction and CVD prevalence across the three genotypes of the $B c l I$ 
polymorphism. To do this, we created dummy variables to compare outcome variables across genotypes, using alternately CG and CC as reference (GG vs CG, GG vs CC, and CG vs CC) (11). Analyses were performed crude (model 1), adjusted for sex, age, cohort, and glucose metabolism status (model 2) and with additional adjustment for smoking status (model 3). Since we previously demonstrated an association of the $B c l$ I GR polymorphism with BMI, we performed an additional mediation analysis to detect if effects of $B c l$ I on vascular risk factors were mediated by BMI (model 4). A two-sided $P$ value $<0.05$ was considered statistically significant. In this study we test associations of $B c l$ I with five main outcome variables, representing two clusters of clinical characteristics (blood pressure and atherothrombosis), and two possible mediators of atherothrombosis (low-grade inflammation and endothelial dysfunction). We did not adjust for multiple testing in this study because of the limited number of clusters tested, the biological plausibility of our hypothesis (35) and the increased chance of type II errors with multiple-testing correction (36).

We performed a power analysis based on our hypothesis that homozygous carriers of the G-allele (GG) will have a more unfavorable cardiovascular profile. In our previous study in the same population we identified 169 homozygous carriers and 519 non-carriers of the $B c l$ I polymorphism. Assuming a normal distribution, this population would result in a power of $80.6 \%$ to demonstrate a significant effect of 0.25 s.D. (i.e. SBP, $5.0 \mathrm{mmHg}$; MAP, $3.0 \mathrm{mmHg}$; IMT, $0.04 \mathrm{~mm}$; and ABI, 0.04) in the analyzed outcome variables.

\section{Additional analyses}

Since the GR might affect some pathways of inflammation and endothelial dysfunction more than others, we investigated the relation between the $B c l$ genotypes and the low-grade inflammation and endothelial dysfunction variables separately.

Additionally, we performed sensitivity analyses. Since participants suffering from acute inflammation could complicate the results $(30,37)$, we repeated the analyses after excluding participants with possible acute inflammation (CRP $>10 \mathrm{mg} / \mathrm{l}, n=145$ ). Furthermore, we adjusted the SBP and MAP analyses for use of antihypertensive medication (yes/no) and we repeated the ABI analyses after excluding participants with an ABI above 1.3 $(n=45)$, since this is sometimes proposed as a cut-off point for a normal $\mathrm{ABI}(27,38)$.
Table 1 General characteristics of the CODAM and Hoorn study population after filtering the individuals missing on $\mathrm{BCll}$. Data are frequencies (\%) or means \pm s.D. Obesity is defined as BMI $\geq 30 \mathrm{~kg} / \mathrm{m}^{2}$.

\begin{tabular}{|c|c|c|c|}
\hline & $\begin{array}{l}\text { CODAM } \\
(n=543)\end{array}$ & $\begin{array}{l}\text { Hoorn } \\
(n=685)\end{array}$ & $\begin{array}{c}\text { Total } \\
(n=1228)\end{array}$ \\
\hline Female (\%) & 38.5 & 50.5 & 45.2 \\
\hline CC/CG/GG (\%) & $42 / 44 / 14$ & $43 / 44 / 14$ & $42 / 44 / 14$ \\
\hline NGM/IGT/T2DM (\%) & $53 / 23 / 24$ & $37 / 23 / 40$ & $44 / 23 / 33$ \\
\hline Age (years) & $59.5 \pm 6.9$ & $68.8 \pm 7.2$ & $64.7 \pm 8.5$ \\
\hline $\mathrm{BMI}\left(\mathrm{kg} / \mathrm{m}^{2}\right)$ & $28.5 \pm 4.3$ & $27.7 \pm 4.1$ & $28.1 \pm 4.2$ \\
\hline Obesity (\%) & 30.6 & 24.2 & 27.1 \\
\hline Current smoking (\%) & 19.9 & 15.7 & 17.6 \\
\hline $\begin{array}{l}\text { Antihypertensive } \\
\text { medication (\%) }\end{array}$ & 38.5 & 39.6 & 39.1 \\
\hline $\mathrm{SBP}(\mathrm{mmHg})$ & $140.0 \pm 19.2$ & $143.0 \pm 20.4$ & $141.6 \pm 19.9$ \\
\hline MAP $(\mathrm{mmHg})$ & $101.2 \pm 11.5$ & $103.2 \pm 12.5$ & $102.3 \pm 12.1$ \\
\hline IMT (mm) & $0.78 \pm 0.16$ & $0.86 \pm 0.17$ & $0.82 \pm 0.17$ \\
\hline $\mathrm{ABI}$ & $1.10 \pm 0.13$ & $1.10 \pm 0.15$ & $1.10 \pm 0.14$ \\
\hline Prevalent CVD (\%) & 27.1 & 55.6 & 42.7 \\
\hline Inflammation score & $-0.339 \pm 0.533$ & $0.281 \pm 0.619$ & $-0.000 \pm 0.658$ \\
\hline ED score & $-0.477 \pm 0.566$ & $0.388 \pm 0.593$ & $-0.004 \pm 0.723$ \\
\hline
\end{tabular}

CC, non-carriers; CG, heterozygous carriers; GG, homozygous carriers; NGM, normal glucose metabolism; IGM, impaired glucose metabolism; T2DM, type 2 diabetes mellitus; SBP, systolic blood pressure; MAP, mean arterial pressure; IMT, intima-media thickness; $A B I$, ankle-brachial index CVD, cardiovascular disease; ED score, endothelial dysfunction score.

\section{Results}

General characteristics of the CODAM and Hoorn study populations are presented in Table 1. The Hoorn study population was older, included more women and more individuals with T2DM and prevalent CVD compared with the CODAM study. Genetic determination of the BclI polymorphism in the combined study populations identified 519 non-carriers (CC) of the G-allele, 540 heterozygous carriers (CG), and 169 homozygous carriers (GG). Genotypes were in Hardy-Weinberg equilibrium $(P>0.05)$ and frequencies did not differ between the two cohorts.

Summary statistics of the study variables across the three genotypes of the BclI GR polymorphism are displayed in Table 2 .

\section{Associations between Bcll polymorphism and blood pressure}

Homozygous carriers of the $B c$ lI polymorphism (GG) had higher SBP $(144.0 \pm 20.7 \mathrm{mmHg}$ vs $140.8 \pm 19.5 \mathrm{mmHg}$ (mean \pm s.D.)) and MAP $(103.8 \pm 12.4 \mathrm{mmHg}$ vs $101.6 \pm$ $12.2 \mathrm{mmHg}$ ) when compared with non-carriers (CC) (Table 2). For MAP this association was significant, also after adjustment for the study covariates (Table 3, models 1-3). For SBP, the association was not statistically significant $(P=0.08$, adjusted for study covariates in the 
Table 2 Distribution of outcome variables across Bc/l genotypes. Data are presented as means \pm s.D., frequencies (\%) or median (interquartile range), as appropriate.

\begin{tabular}{|c|c|c|c|}
\hline & CC & CG & GG \\
\hline$n$ & 519 & 540 & 169 \\
\hline SBP $(\mathrm{mmHg})$ & $140.8 \pm 19.5$ & $141.8 \pm 20.0$ & $144.0 \pm 20.7$ \\
\hline $\mathrm{MAP}(\mathrm{mmHg})$ & $101.6 \pm 12.2$ & $102.4 \pm 11.9$ & $103.8 \pm 12.4$ \\
\hline IMT (mm) & $0.83 \pm 0.17$ & $0.82 \pm 0.17$ & $0.84 \pm 0.18$ \\
\hline$A B I$ & $1.10 \pm 0.14$ & $1.11 \pm 0.14$ & $1.08 \pm 0.13$ \\
\hline $\begin{array}{l}\text { Prevalent } \\
\text { CVD (\%) }\end{array}$ & 44.1 & 40.5 & 45.5 \\
\hline $\begin{array}{l}\text { Inflammation } \\
\text { score }\end{array}$ & $0.009 \pm 0.694$ & $-0.008 \pm 0.651$ & $-0.006 \pm 0.567$ \\
\hline ED score & $-0.009 \pm 0.713$ & $-0.009 \pm 0.734$ & $0.027 \pm 0.724$ \\
\hline BMI & $27.9 \pm 4.2$ & $27.9 \pm 4.1$ & $28.9 \pm 4.5$ \\
\hline
\end{tabular}

CC, non-carriers; CG, heterozygous carriers; GG, homozygous carriers; SBP, systolic blood pressure; MAP, mean arterial pressure; IMT, intima-media thickness; $A B I$, ankle-brachial index; CVD, cardiovascular disease; ED score, endothelial dysfunction score.

full model; Table 3, model 3). Homozygous carriers did not have a significantly higher SBP and MAP when compared with heterozygous carriers (CG).

In the additional mediation analysis we adjusted the model for BMI. After this adjustment, the association between $B c l$ I and blood pressure was attenuated. BMI accounted for $21 \%$ of the association between $B c l$ I and MAP (Table 3, model 4; unstandardized regression coefficient decreased from 2.201 to 1.731 ).

\section{Associations between $B c / l$ and atherosclerosis and CVD prevalence}

Homozygous carriers of the BclI polymorphism (GG) had a lower ABI $(1.08 \pm 0.13$ vs $1.10 \pm 0.14)$ compared with heterozygous carriers (CG) (Table 2). This association was only significant in the crude analysis and after adjustment for sex, age, cohort, and glucose metabolism status (Table 4, models 1-2). Additional adjustment for smoking status attenuated the association and statistical significance was no longer observed ( $P=0.06$, Table 4 , model 3 ). No differences in $\mathrm{ABI}$ were demonstrated between homozygous carriers and non-carriers (CC). Also, no association with cIMT and prevalent CVD was observed for $B c l$ (Table 4).

\section{Associations between $B c / l$ and inflammation and endothelial dysfunction}

Composite scores of inflammation and endothelial dysfunction were not significantly different across the BclI genotypes (Table 5).

\section{Additional analyses}

When investigating the effect of $B c l$ I on the individual variables of low-grade inflammation, we observed a significantly lower IL6 level for homozygous carriers (GG) when compared with non-carriers (CC), but only after adjusting for BMI in the mediation analysis (Supplemental Table 1 , model 4 , see section on supplementary data given at the end of this). No other associations between $B c l$ I and variables of low-grade inflammation and endothelial dysfunction were found (see Supplemental Tables 1 and 2).

In the sensitivity analyses, exclusion of individuals with possible acute inflammation strengthened the association between $B c l$ I and blood pressure, IMT and ABI

Table 3 Associations of Bc/l polymorphism with SBP and MAP. Comparison across genotypes.

\begin{tabular}{|c|c|c|c|c|c|c|}
\hline \multirow[b]{2}{*}{ Model } & \multicolumn{2}{|c|}{ GG vs CG } & \multicolumn{2}{|c|}{ GG vs CC } & \multicolumn{2}{|c|}{ CG vs CC } \\
\hline & $\beta$ & $95 \% \mathrm{Cl}$ & $\beta$ & $95 \% \mathrm{Cl}$ & $\beta$ & $95 \% \mathrm{Cl}$ \\
\hline \multicolumn{7}{|l|}{ SBP } \\
\hline 1 & 2.311 & $-1.178 ; 5.800$ & 3.329 & $-0.171 ; 6.830$ & 1.018 & $-1.404 ; 3.441$ \\
\hline 2 & 2.022 & $-1.250 ; 5.295$ & 2.844 & $-0.440 ; 6.128$ & 0.821 & $-1.451 ; 3.093$ \\
\hline 3 & 2.146 & $-1.122 ; 5.414$ & 2.977 & $-0.303 ; 6.257$ & 0.831 & $-1.437 ; 3.099$ \\
\hline 4 & 1.566 & $-1.684 ; 4.815$ & 2.416 & $-0.845 ; 5.677$ & 0.850 & $-1.398 ; 3.099$ \\
\hline \multicolumn{7}{|l|}{ MAP } \\
\hline 1 & 1.376 & $-0.740 ; 3.492$ & 2.241 & $0.118 ; 4.363^{*}$ & 0.865 & $-0.604 ; 2.334$ \\
\hline 2 & 1.222 & $-0.823 ; 3.266$ & 2.075 & $0.023 ; 4.127 *$ & 0.853 & $-0.566 ; 2.273$ \\
\hline 3 & 1.339 & $-0.697 ; 3.374$ & 2.201 & $0.158 ; 4.245^{*}$ & 0.863 & $-0.550 ; 2.276$ \\
\hline 4 & 0.852 & $-1.158 ; 2.861$ & 1.731 & $-0.286 ; 3.747$ & 0.879 & $-0.512 ; 2.269$ \\
\hline
\end{tabular}

Model 1, crude analysis; model 2, adjusted for sex, age, cohort, and glucose metabolism status; model 3, model $2+$ smoking. Mediation analysis: model 4, model 3+BMI. CC, non-carriers; CG, heterozygous carriers; GG, homozygous carriers; $\beta$, unstandardized regression coefficient: indicates the difference in dependent variable (in its units, see Table 2 ) between groups being compared; SBP, systolic blood pressure; MAP, mean arterial pressure. ${ }^{\star} P<0.05$. $n=1209$. 
Table 4 Associations of $B C /$ polymorphism with IMT, ABI, and prevalent CVD. Comparison across genotypes.

\begin{tabular}{l}
\hline Model \\
\hline IMT \\
1 \\
2 \\
3 \\
4 \\
ABI \\
1 \\
2 \\
3 \\
4 \\
Prevalent CVD \\
1 \\
2 \\
3 \\
4
\end{tabular}

\begin{tabular}{cc}
\hline & GG vs \\
$\beta$ & \\
0.023 \\
0.022 \\
0.022 \\
0.018 \\
$\beta$ \\
-0.025 \\
-0.023 \\
-0.021 \\
-0.020 \\
OR \\
1.213 \\
1.237 \\
1.229 \\
1.196 \\
\hline
\end{tabular}

\begin{tabular}{c} 
GG vs CG \\
$95 \% \mathrm{Cl}$ \\
$-0.008 ; 0.055$ \\
$-0.007 ; 0.050$ \\
$-0.006 ; 0.051$ \\
$-0.010 ; 0.046$ \\
$95 \% \mathrm{Cl}$ \\
$-0.048 ;-0.002^{*}$ \\
$-0.045 ;-0.001 *$ \\
$-0.043 ; 0.001$ \\
$-0.042 ; 0.002$ \\
$95 \% \mathrm{Cl}$ \\
$0.850 ; 1.730$ \\
$0.846 ; 1.808$ \\
$0.841 ; 1.797$ \\
$0.817 ; 1.750$ \\
\hline
\end{tabular}

\begin{tabular}{cc}
\hline & GG vs \\
\hline$\beta$ & 0.015 \\
0.014 \\
0.015 \\
0.011 \\
$\beta$ \\
-0.022 \\
-0.017 \\
-0.014 \\
-0.014 \\
OR \\
1.025 \\
1.035 \\
1.025 \\
0.996 \\
\hline
\end{tabular}

\begin{tabular}{c} 
CC \\
$95 \% \mathrm{Cl}$ \\
$-0.017 ; 0.046$ \\
$-0.014 ; 0.043$ \\
$-0.013 ; 0.044$ \\
$-0.018 ; 0.039$ \\
$95 \% \mathrm{Cl}$ \\
$-0.045 ; 0.001$ \\
$-0.039 ; 0.005$ \\
$-0.036 ; 0.008$ \\
$-0.036 ; 0.008$ \\
$95 \% \mathrm{Cl}$ \\
$0.719 ; 1.461$ \\
$0.708 ; 1.513$ \\
$0.701 ; 1.499$ \\
$0.680 ; 1.458$ \\
\hline
\end{tabular}

\begin{tabular}{cc}
\hline \multicolumn{2}{c}{ CG vs CC } \\
\hline$\beta$ & $95 \% \mathrm{Cl}$ \\
-0.009 & $-0.031 ; 0.013$ \\
-0.007 & $-0.027 ; 0.012$ \\
-0.007 & $-0.027 ; 0.012$ \\
-0.007 & $-0.027 ; 0.012$ \\
$\beta$ & $95 \% \mathrm{Cl}$ \\
0.003 & $-0.013 ; 0.019$ \\
0.006 & $-0.009 ; 0.022$ \\
0.007 & $-0.009 ; 0.022$ \\
0.007 & $-0.009 ; 0.022$ \\
OR & $95 \% \mathrm{Cl}$ \\
0.845 & $0.659 ; 1.083$ \\
0.837 & $0.642 ; 1.091$ \\
0.834 & $0.640 ; 1.088$ \\
0.833 & $0.638 ; 1.087$ \\
\hline
\end{tabular}

Model 1, crude analysis; model 2, adjusted for sex, age, cohort, and glucose metabolism status; model 3, model 2+smoking. Mediation analysis: model 4, model 3+BMI. CC, non-carriers; CG, heterozygous carriers; GG, homozygous carriers; $\beta$, unstandardized regression coefficient: indicates the difference in dependent variable (in its units, see Table 2) between groups being compared; IMT, intima-media thickness; ABI, ankle-brachial index; CVD, cardiovascular disease; OR, odds ratio. Note that the association of the $B C / l$ polymorphisms with CVD was calculated with logistic regression. ${ }^{*} P<0.05$. $n=1114$ for IMT analyses, $n=1170$ for $\mathrm{ABI}$ analyses, and $n=1189$ for prevalent CVD analyses.

(see Supplemental Tables 3 and 4, see section on supplementary data given at the end of this article). Associations with prevalent CVD, low-grade inflammation and endothelial dysfunction did not materially change (results not shown). Furthermore, adjustment of blood pressure analyses for antihypertensive medication did not substantially change the association between $\mathrm{Bcl}$ I and blood pressure (results not shown). When excluding individuals with an ABI above 1.3, the association between $B c l$ I and ABI was slightly attenuated (Supplemental Table 5).

\section{Discussion}

In this study containing data from two large Dutch population-based cohorts we evaluated the cardiovascular associations of the GR polymorphism BclI. We demonstrated that homozygous carriers of the BclI G-allele had a significantly higher MAP compared with non-carriers, independent of sex, age, cohort, glucose metabolism status, and smoking. Although homozygous carriers had a lower ABI in comparison to heterozygous carriers after adjustment for sex, age, cohort, and glucose metabolism

Table 5 Associations of $B c / l$ polymorphism with the natural logarithms of inflammatory markers and markers of endothelial dysfunction. Comparison across genotypes.

\begin{tabular}{|c|c|c|c|c|c|c|}
\hline \multirow[b]{2}{*}{ Model } & \multicolumn{2}{|c|}{ GG vs CG } & \multicolumn{2}{|c|}{ GG vs CC } & \multicolumn{2}{|c|}{ CG vs CC } \\
\hline & $\beta$ & $95 \% \mathrm{Cl}$ & $\beta$ & $95 \% \mathrm{Cl}$ & $\beta$ & $95 \% \mathrm{Cl}$ \\
\hline \multicolumn{7}{|c|}{ Inflammation score } \\
\hline 1 & -0.009 & $-0.126 ; 0.107$ & -0.022 & $-0.139 ; 0.094$ & -0.013 & $-0.094 ; 0.068$ \\
\hline 2 & -0.018 & $-0.117 ; 0.081$ & -0.030 & $-0.130 ; 0.070$ & -0.012 & $-0.081 ; 0.057$ \\
\hline 3 & -0.028 & $-0.126 ; 0.070$ & -0.040 & $-0.139 ; 0.058$ & -0.012 & $-0.080 ; 0.056$ \\
\hline 4 & -0.059 & $-0.155 ; 0.037$ & -0.069 & $-0.165 ; 0.027$ & -0.010 & $-0.077 ; 0.056$ \\
\hline \multicolumn{7}{|c|}{ ED score } \\
\hline 1 & 0.021 & $-0.107 ; 0.149$ & 0.025 & $-0.104 ; 0.154$ & 0.004 & $-0.085 ; 0.093$ \\
\hline 2 & 0.012 & $-0.086 ; 0.110$ & 0.027 & $-0.071 ; 0.126$ & 0.015 & $-0.053 ; 0.083$ \\
\hline 3 & 0.007 & $-0.091 ; 0.105$ & 0.022 & $-0.076 ; 0.120$ & 0.015 & $-0.053 ; 0.083$ \\
\hline 4 & -0.026 & $-0.121 ; 0.070$ & -0.008 & $-0.104 ; 0.087$ & 0.017 & $-0.049 ; 0.083$ \\
\hline
\end{tabular}

Model 1, crude analysis; model 2, adjusted for sex, age, cohort, and glucose metabolism status; model 3, model $2+$ smoking. Mediation analysis: model 4 model 3+BMI. CC, non-carriers; CG, heterozygous carriers; GG, homozygous carriers; $\beta$, unstandardized regression coefficient: indicates the difference in dependent variable (in its units) between groups being compared; Inflammation score: averaged Z-score of CRP, IL6, IL8, TNF $\alpha$, SAA, and sICAM1; ED score, Endothelial dysfunction score: averaged $Z$-score of sICAM1, VWF, sE-selectin, and sVCAM1. * $P<0.05$. $n=1178$ for inflammation score analyses and $n=1165$ for endothelial dysfunction score analyses. 
status, we found no associations of $B c l$ I with SBP, IMT, ABI, composite scores for low-grade inflammation and endothelial dysfunction or CVD after adjustment for all study covariates in the full model. Our findings suggest that an increased sensitivity of the GR appears to have limited effects on cardiovascular variables.

In this study we found no significant changes in SBP across the $B c l$ I genotypes. However, we did demonstrate a significantly higher MAP in homozygous carriers of the BclI polymorphism when compared with non-carriers. Although SBP is clinically regarded as the most important blood pressure measurement, MAP has shown to be very informative in the prediction of stroke and ischemic heart disease mortality (39). Since we previously showed greater total body fatness in homozygous BclI carriers (11) (Table 2), and obesity is a known risk factor for hypertension, BMI could be an important mediator in the cardiovascular effects of $B c l$. We performed a mediation analysis to investigate the extent of the potential role of BMI as a mediator in the association of $B c l$ with blood pressure. BMI accounted for roughly $20 \%$ of the effect of $B c l$ I on blood pressure (Table 3, model 4), indicating that the effect of the $B c l$ I polymorphism on blood pressure may be partly mediated by increased BMI in homozygous carriers. Adjustment for use of antihypertensive medication did not change the associations. Earlier studies examining effects of $B c l$ I on blood pressure showed inconsistent results in varying populations $(10,12,14$, 15, 16). A large study in a population enriched with individuals with hypertension demonstrated no association between $\mathrm{Bcl}$ I and blood pressure (17). These analyses were adjusted, however, for multiple covariates, including BMI, and could therefore mask the effect of $\mathrm{Bcl}$ I on blood pressure that is possibly partly mediated by BMI. This hypothesis is supported by a Chinese study in a large healthy cohort showing a strong association of BclI with SBP after adjustment only for sex and age (13). To our knowledge, we are the first large observational study reporting higher MAP in homozygous carriers of the $B c l$ I polymorphism.

We demonstrated a significantly lower ABI in homozygous carriers of the BclI polymorphism compared with heterozygous carriers in the crude analysis and adjusted for sex, age, cohort, and glucose metabolism status. However, after additional adjustment for smoking status, this association was no longer significant, implying that these results should be interpreted with caution. Since some consider correction for potential confounders debatable in a study of genetic variants (40), the strength of the association between $\mathrm{BclI}$ and the outcome variables in our adjusted models might be subject to overcorrection. Next, we investigated whether BMI also mediated the association between BclI and ABI. Adding BMI to the model did not materially change the association, indicating that the effect of $B c l$ I on ABI is not mediated by an increase in BMI per se. A previous observational study also did not report an association between BclI and cIMT (18), which is in accordance with our results. Although it might seem peculiar that the $B c l$ I polymorphism was associated with a decrease in ABI whereas cIMT was unaffected, we believe this may represent different pathophysiology of atherosclerotic disease in different vascular territories, where cIMT better represents central atherosclerosis and ABI better represents peripheral atherosclerosis (41).

In our study we did not find an association between $B c l$ I and prevalent CVD, which is in line with some other observational studies $(18,19,20)$. Others have reported higher CVD risk for male individuals carrying the $B c l I$ G-allele (16); however, that study was performed in a cohort of individuals with familial hypercholesterolemia. The current study was performed in a cohort enriched with individuals with T2DM and individuals with an elevated CVD risk to increase statistical power. We found no interactions between the $B c l$ I genotype and sex for the CVD analyses, and concordantly, stratification for sex did not alter the observations for CVD (results not shown).

No associations of $B c l$ I with robust scores for low-grade inflammation and endothelial dysfunction were found in the present study. In our additional analyses we demonstrated a significantly lower IL6 level for homozygous carriers compared with non-carriers, but only after adjustment for BMI. Possibly, anti-inflammatory actions only become apparent when adjusting for pro-inflammatory metabolic traits associated with the polymorphism. However, due to the number of statistical tests performed in these analyses, these findings may well be spurious. The role of glucocorticoids in inflammation is very complex since they are able to exert both pro- and anti-inflammatory effects through several pathways (1). Although one case-control study has shown a lower risk of developing rheumatoid arthritis for BclI-carriers (42), most studies do not suggest the presence of $B c l I$ is directly related to inflammation $(18,43)$. In line with these observations, our null findings in this large study suggest that the $B c l$ I polymorphism mainly has metabolic effects, and that its role in chronic low-grade inflammation is limited, as is supported by a previous cohort study (18).

At present, it is not exactly known through which mechanism the BclI polymorphism leads to a more sensitive GR. The GR can activate or repress target genes 
by binding of the receptor to specific glucocorticoidresponsive elements. Additionally, the GR can alter transcription by interacting with other transcription factors (44). These different pathways result in highly pleiotropic effects of the GR, making it more difficult to speculate about the effects across different $B c l$ genotypes. Our data demonstrate that MAP is higher for homozygous carriers compared with non-carriers, while $\mathrm{ABI}$ is different only when comparing homozygous carriers with heterozygous carriers. Our previous study revealed similar findings, demonstrating a higher HOMA-index for homozygous carriers compared with heterozygous carriers only (11). Thus, even though the exact mechanism might not be known so far, on the basis of our results we are able to conclude that homozygous carriers of the $B c l$ polymorphism seem to consistently express a more unfavorable metabolic and cardiovascular phenotype.

A major strength of our study is the large, metabolically well-defined population, enriched with individuals at risk for cardiometabolic disease, improving its power in analyzing cardiovascular outcomes. On the other hand, a limitation of our study was that we were unable to investigate incident CVD due to the cross-sectional design of the study. Also, since only non-fatal CVD is reported in this study, we cannot exclude potential associations between $B c l$ and cardiovascular mortality. Nevertheless, our comprehensively characterized cohort did enable us to evaluate the role of $B c l$ across several traits of CVD, including low-grade inflammation and endothelial dysfunction.

In conclusion, our study demonstrated that homozygous carriers of the $B c l$ polymorphism of the GR gene have an increased MAP and possibly a decreased ABI, since adjustment for all study covariates in the full model attenuated the effect on ABI. We found no association of the BclI polymorphism with SBP, cIMT, low-grade inflammation, endothelial dysfunction, and prevalent CVD. Although the results of our study support the hypothesis that this common polymorphism can have cardiovascular implications, the effects on the cardiovascular variables appear to be limited and partly mediated by the unfavorable metabolic phenotype exerted by BclI. Since both the actions of the GR and the pathophysiology of CVD are complex and multifactorial, further studies are necessary to understand mechanisms through which $\mathrm{BclI}$ causes its metabolic and cardiovascular effects.

Supplementary data

This is linked to the online version of the paper at http://dx.doi.org/10.1530/ EJE-15-0381.
Declaration of interest

The authors declare that there is no conflict of interest that could be perceived as prejudicing the impartiality of the research reported.

\section{Funding}

The CODAM study has been supported by grants of the Netherlands Organization for Scientific Research (940-35-034) and the Dutch Diabetes Research Foundation (98.901)

\section{Author contribution statement}

All authors participated sufficiently in the work to take public responsibility for its content.

\section{References}

1 Busillo JM \& Cidlowski JA. The five Rs of glucocorticoid action during inflammation: ready, reinforce, repress, resolve, and restore. Trends in Endocrinology and Metabolism 201324 109-119. (doi:10.1016/j.tem. 2012.11.005)

2 Fraser R, Davies DL \& Connell JM. Hormones and hypertension. Clinical Endocrinology 198931 701-746. (doi:10.1111/j.1365-2265.1989. tb01295.x)

3 Saruta T, Suzuki H, Handa M, Igarashi Y, Kondo K \& Senba S. Multiple factors contribute to the pathogenesis of hypertension in Cushing's syndrome. Journal of Clinical Endocrinology and Metabolism 198662 275-279. (doi:10.1210/jcem-62-2-275)

4 Walker BR. Glucocorticoids and cardiovascular disease. European Journal of Endocrinology 2007157 545-559. (doi:10.1530/EJE-07-0455)

5 Arnaldi G, Angeli A, Atkinson AB, Bertagna X, Cavagnini F, Chrousos GP, Fava GA, Findling JW, Gaillard RC, Grossman AB et al. Diagnosis and complications of Cushing's syndrome: a consensus statement. Journal of Clinical Endocrinology and Metabolism $2003 \mathbf{8 8}$ 5593-5602. (doi:10.1210/jc.2003-030871)

6 Etxabe J \& Vazquez JA. Morbidity and mortality in Cushing's disease: an epidemiological approach. Clinical Endocrinology 199440 479-484. (doi:10.1111/j.1365-2265.1994.tb02486.x)

7 Neary NM, Booker OJ, Abel BS, Matta JR, Muldoon N, Sinaii N, Pettigrew RI, Nieman LK \& Gharib AM. Hypercortisolism is associated with increased coronary arterial atherosclerosis: analysis of noninvasive coronary angiography using multidetector computerized tomography. Journal of Clinical Endocrinology and Metabolism 201398 2045-2052. (doi:10.1210/jc.2012-3754)

8 Huizenga NA, Koper JW, De Lange P, Pols HA, Stolk RP, Burger H, Grobbee DE, Brinkmann AO, De Jong FH \& Lamberts SW. A polymorphism in the glucocorticoid receptor gene may be associated with and increased sensitivity to glucocorticoids in vivo. Journal of Clinical Endocrinology and Metabolism 199883 144-151. (doi:10.1210/ jcem.83.1.4490)

9 van Rossum EF \& Lamberts SW. Polymorphisms in the glucocorticoid receptor gene and their associations with metabolic parameters and body composition. Recent Progress in Hormone Research 200459 333-357. (doi:10.1210/rp.59.1.333)

10 van Rossum EF, Koper JW, van den Beld AW, Uitterlinden AG, Arp P, Ester W, Janssen JA, Brinkmann AO, de Jong FH, Grobbee DE et al. Identification of the $B c l$ polymorphism in the glucocorticoid receptor gene: association with sensitivity to glucocorticoids in vivo and body mass index. Clinical Endocrinology 200359 585-592. (doi:10.1046/ j.1365-2265.2003.01888.x 
11 Geelen CC, van Greevenbroek MM, van Rossum EF, Schaper NC, Nijpels G, 't Hart LM, Schalkwijk CG, Ferreira I, van der Kallen CJ, Sauerwein HP et al. Bcll glucocorticoid receptor polymorphism is associated with greater body fatness: the Hoorn and CODAM studies. Journal of Clinical Endocrinology and Metabolism 201398 E595-E599. (doi:10.1210/jc.2012-3442)

12 Moreira RP, Gomes LG, Mendonca BB \& Bachega TA. Impact of glucocorticoid receptor gene polymorphisms on the metabolic profile of adult patients with the classical form of 21-hydroxylase deficiency. PLOS ONE 20127 e44893. (doi:10.1371/journal.pone.0044893)

13 Yan YX, Dong J, Wu LJ, Shao S, Zhang J, Zhang L, Wang W, He Y \& Liu YQ. Associations between polymorphisms in the glucocorticoidreceptor gene and cardiovascular risk factors in a Chinese population. Journal of Epidemiology 201323 389-395. (doi:10.2188/jea.JE20130035)

14 Watt GC, Harrap SB, Foy CJ, Holton DW, Edwards HV, Davidson HR, Connor JM, Lever AF \& Fraser R. Abnormalities of glucocorticoid metabolism and the renin-angiotensin system: a four-corners approach to the identification of genetic determinants of blood pressure. Journal of Hypertension 199210 473-482. (doi:10.1097/00004872199205000-00011)

15 Di Blasio AM, van Rossum EF, Maestrini S, Berselli ME, Tagliaferri M, Podesta F, Koper JW, Liuzzi A \& Lamberts SW. The relation between two polymorphisms in the glucocorticoid receptor gene and body mass index, blood pressure and cholesterol in obese patients. Clinical Endocrinology 200359 68-74. (doi:10.1046/j.1365-2265.2003.01798.x)

16 Koeijvoets KC, van der Net JB, van Rossum EF, Steyerberg EW, Defesche JC, Kastelein JJ, Lamberts SW \& Sijbrands EJ. Two common haplotypes of the glucocorticoid receptor gene are associated with increased susceptibility to cardiovascular disease in men with familial hypercholesterolemia. Journal of Clinical Endocrinology and Metabolism 200893 4902-4908. (doi:10.1210/jc.2008-0813)

17 Chung CC, Shimmin L, Natarajan S, Hanis CL, Boerwinkle E \& Hixson JE. Glucocorticoid receptor gene variant in the $3^{\prime}$ untranslated region is associated with multiple measures of blood pressure. Journal of Clinical Endocrinology and Metabolism 200994 268-276. (doi:10.1210/ jc.2008-1089)

18 van den Akker EL, Koper JW, van Rossum EF, Dekker MJ, Russcher H, de Jong FH, Uitterlinden AG, Hofman A, Pols HA, Witteman JC et al. Glucocorticoid receptor gene and risk of cardiovascular disease. Archives of Internal Medicine 2008168 33-39. (doi:10.1001/archinternmed.2007.41)

19 Kuningas M, Mooijaart SP, Slagboom PE, Westendorp RG \& van Heemst D. Genetic variants in the glucocorticoid receptor gene (NR3C1) and cardiovascular disease risk. The Leiden 85-plus Study. Biogerontology 20067 231-238. (doi:10.1007/s10522-006-9021-2)

20 Alevizaki M, Cimponeriu A, Lekakis J, Papamichael C \& Chrousos GP. High anticipatory stress plasma cortisol levels and sensitivity to glucocorticoids predict severity of coronary artery disease in subjects undergoing coronary angiography. Metabolism 200756 222-226. (doi:10.1016/j.metabol.2006.09.017)

21 Ross R. Atherosclerosis - an inflammatory disease. New England Journal of Medicine 1999340 115-126. (doi:10.1056/ NEJM199901143400207)

22 De Caterina R. Endothelial dysfunctions: common denominators in vascular disease. Current Opinion in Lipidology 200011 9-23. (doi:10.1097/00041433-200002000-00003)

23 Snijder MB, Dekker JM, Visser M, Bouter LM, Stehouwer CD, Yudkin JS, Heine RJ, Nijpels G, Seidell JC \& Hoorn study. Trunk fat and leg fat have independent and opposite associations with fasting and postload glucose levels: the Hoorn study. Diabetes Care 200427 372-377. (doi:10.2337/diacare.27.2.372)

24 Jacobs M, van Greevenbroek MM, van der Kallen CJ, Ferreira I, Blaak EE, Feskens EJ, Jansen EH, Schalkwijk CG \& Stehouwer CD. Low-grade inflammation can partly explain the association between the metabolic syndrome and either coronary artery disease or severity of peripheral arterial disease: the CODAM study. European Journal of Clinical
Investigation 200939 437-444. (doi:10.1111/j.1365-2362.2009. 02129.x)

25 Engelen L, Ferreira I, Gaens KH, Henry RM, Dekker JM, Nijpels G, Heine RJ, 't Hart LM, van Greevenbroek MM, van der Kallen CJ et al. The association between the $-374 \mathrm{~T} / \mathrm{A}$ polymorphism of the receptor for advanced glycation endproducts gene and blood pressure and arterial stiffness is modified by glucose metabolism status: the Hoorn and CoDAM studies. Journal of Hypertension 201028 285-293. (doi:10.1097/ HJH.0b013e3283330931)

26 Henry RM, Ferreira I, Kostense PJ, Dekker JM, Nijpels G, Heine RJ, Kamp O, Bouter LM \& Stehouwer CD. Type 2 diabetes is associated with impaired endothelium-dependent, flow-mediated dilation, but impaired glucose metabolism is not; the Hoorn Study. Atherosclerosis 2004174 49-56. (doi:10.1016/j.atherosclerosis.2004.01.002)

27 Hertle E, van Greevenbroek MM, Arts IC, van der Kallen CJ, Geijselaers SL, Feskens EJ, Jansen EH, Schalkwijk CG \& Stehouwer CD. Distinct associations of complement C3a and its precursor C3 with atherosclerosis and cardiovascular disease. The CODAM study. Thrombosis and Haemostasis 2014111 1102-1111. (doi:10.1160/TH1310-0831)

28 Henry RM, Kostense PJ, Spijkerman AM, Dekker JM, Nijpels G, Heine RJ, Kamp O, Westerhof N, Bouter LM, Stehouwer CD et al. Arterial stiffness increases with deteriorating glucose tolerance status: the Hoorn Study. Circulation 2003107 2089-2095. (doi:10.1161/01.CIR.0000065222. 34933.FC)

29 van Bussel BC, Henry RM, Schalkwijk CG, Dekker JM, Nijpels G \& Stehouwer CD. Low-grade inflammation, but not endothelial dysfunction, is associated with greater carotid stiffness in the elderly: the Hoorn Study. Journal of Hypertension 201230 744-752. (doi:10.1097/ HJH.0b013e328350a487)

30 van Woudenbergh GJ, Theofylaktopoulou D, Kuijsten A, Ferreira I, van Greevenbroek MM, van der Kallen CJ, Schalkwijk CG, Stehouwer CD, Ocke MC, Nijpels G et al. Adapted dietary inflammatory index and its association with a summary score for low-grade inflammation and markers of glucose metabolism: the Cohort study on Diabetes and Atherosclerosis Maastricht (CODAM) and the Hoorn study. American Journal of Clinical Nutrition 201398 1533-1542. (doi:10.3945/ajcn.112. 056333)

31 van Bussel BC, Ferreira I, van de Waarenburg MP, van Greevenbroek MM, van der Kallen CJ, Henry RM, Feskens EJ, Stehouwer CD \& Schalkwijk CG. Multiple inflammatory biomarker detection in a prospective cohort study: a cross-validation between well-established single-biomarker techniques and an electrochemiluminescense-based multi-array platform. PLoS ONE 20138 e58576. (doi:10.1371/journal.pone.0058576)

32 van Greevenbroek MM, Jacobs M, van der Kallen CJ, Vermeulen VM, Jansen EH, Schalkwijk CG, Ferreira I, Feskens EJ \& Stehouwer CD. The cross-sectional association between insulin resistance and circulating complement C3 is partly explained by plasma alanine aminotransferase, independent of central obesity and general inflammation (the CODAM study). European Journal of Clinical Investigation 201141 372-379. (doi:10.1111/j.1365-2362.2010.02418.x)

33 Hertle E, van Greevenbroek MM, Arts IC, van der Kallen CJ, Feskens EJ, Schalkwijk CG \& Stehouwer CD. Complement activation products C5a and sC5b-9 are associated with low-grade inflammation and endothelial dysfunction, but not with atherosclerosis in a cross-sectional analysis: the CODAM study. International Journal of Cardiology 2014174 400-403. (doi:10.1016/j.ijcard.2014.04.057)

34 Schram MT \& Stehouwer CD. Endothelial dysfunction, cellular adhesion molecules and the metabolic syndrome. Hormone and Metabolic Research 200537 (Suppl 1) 49-55. (doi:10.1055/s-2005-861363)

35 Nuzzo R. Scientific method: statistical errors. Nature 2014506 150-152. (doi:10.1038/506150a)

36 Rothman KJ. No adjustments are needed for multiple comparisons. Epidemiology 19901 43-46. (doi:10.1097/00001648-199001000-00010) 
37 Pearson TA, Mensah GA, Alexander RW, Anderson JL, Cannon RO III, Criqui M, Fadl YY, Fortmann SP, Hong Y, Myers GL et al. Markers of inflammation and cardiovascular disease: application to clinical and public health practice: a statement for healthcare professionals from the Centers for Disease Control and Prevention and the American Heart Association. Circulation 2003107 499-511. (doi:10.1161/01.CIR. 0000052939.59093.45)

38 Potier L, Abi Khalil C, Mohammedi K \& Roussel R. Use and utility of ankle brachial index in patients with diabetes. European Journal of Vascular and Endovascular Surgery 201141 110-116. (doi:10.1016/j.ejvs. 2010.09.020)

39 Lewington S, Clarke R, Qizilbash N, Peto R, Collins R \& Prospective Studies C. Age-specific relevance of usual blood pressure to vascular mortality: a meta-analysis of individual data for one million adults in 61 prospective studies. Lancet 2002360 1903-1913. (doi:10.1016/ S0140-6736(02)11911-8)

40 Sheehan NA, Didelez V, Burton PR \& Tobin MD. Mendelian randomisation and causal inference in observational epidemiology. PLoS Medicine 20085 e177. (doi:10.1371/journal.pmed.0050177)
41 Weir-McCall JR, Khan F, Lambert MA, Adamson CL, Gardner M, Gandy SJ, Ramkumar PG, Belch JJ, Struthers AD, Rauchhaus P et al. Common carotid intima media thickness and ankle-brachial pressure index correlate with local but not global atheroma burden: a cross sectional study using whole body magnetic resonance angiography. PLOS ONE 20149 e99190. (doi:10.1371/journal.pone.0099190)

42 van Oosten MJ, Dolhain RJ, Koper JW, van Rossum EF, Emonts M, Han KH, Wouters JM, Hazes JM, Lamberts SW \& Feelders RA. Polymorphisms in the glucocorticoid receptor gene that modulate glucocorticoid sensitivity are associated with rheumatoid arthritis. Arthritis Research \& Therapy 201012 R159. (doi:10.1186/ar3118)

43 Donn R, Payne D \& Ray D. Glucocorticoid receptor gene polymorphisms and susceptibility to rheumatoid arthritis. Clinical Endocrinology 200767 342-345. (doi:10.1111/j.1365-2265.2007. 02887.x)

44 Schaaf MJ \& Cidlowski JA. Molecular determinants of glucocorticoid receptor mobility in living cells: the importance of ligand affinity. Molecular and Cellular Biology 200323 1922-1934. (doi:10.1128/MCB. 23.6.1922-1934.2003)

Received 10 April 2015

Revised version received 19 June 2015

Accepted 2 July 2015 